\title{
Design and Prototyping of Powered Sliding Door for Light Commercial Vehicles
}

\author{
Uğur Demir ${ }^{1 *}$ \\ 0000-0001-7557-3637 \\ ${ }^{1}$ Mechatronics Engineering Department, Faculty of Technology, Marmara University, Istanbul, 34710, Turkey
}

\section{Abstract}

This study presents the powered sliding door (PSLD) design and prototype for light commercial vehicles. First of all, the literature and patent research are done. And the state of the art for sliding door mechanism types and electronic control methods are investigated. Then, the requirements, specifications and regulations of original equipment manufacturers (OEMs) are dealt with and design requirements and criteria are determined. The performance requirements of the electric motor for the sliding door main unit are calculated according to the design criteria and the vehicle door. The main unit is designed to actuate the sliding door as per the design criteria by defining the electric motor. The vehicle door must be unlocked before opening or closing the door. Unlocking actuator is developed for this process. Subsequently, the electronic control unit (DCU) is designed to control the components and actuators. In order to solve the problem frequently encountered in obstacle detection when the vehicle is on a slope, the current limits are updated according to the current information read from the electric motor and the vehicle slope information, and the obstacle detection is tried to be performed. Finally, testing and verification studies are performed according to the design requirements.

Keywords: Powered sliding door; automotive actuators; obstacle detection; product development process

\section{Research Article}

https://doi.org/10.30939/ijastech..871619

$\begin{array}{ll}\text { Received } & 31.01 .2021 \\ \text { Revised } & 10.03 .2021 \\ \text { Accepted } & 17.03 .2021\end{array}$

* Corresponding author

Uğur Demir

udemir@marmara.edu.tr

Address: Mechatronics Engineering Department, Faculty of Technology, Marmara University, Istanbul, 34710, Turkey

Tel:+ 905344787370

\section{Introduction}

Due to user demands and ease of use, the most used door types are conventional (mechanisms that allow movement to the outside or inside by rotating around an angle with a hinge) and sliding doors. Today's technological developments create the need for electrically controlled sliding door systems especially in light and heavy commercial vehicles for service purposes [1]. A view of a sliding door for light commercial vehicles is shown in Figure 1.

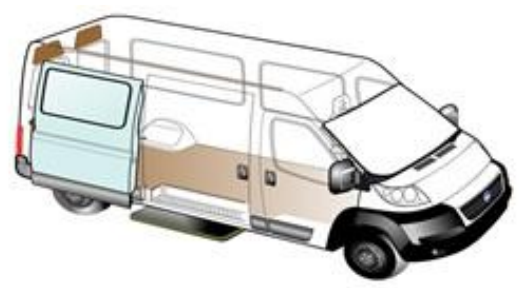

Fig. 1. The powered sliding door of light commercial vehicles

Generally, a powered sliding door system includes the door, power drive system, lock mechanism, and a single motor that operates both the lock and the power drive mechanism. The power drive system is connected with the door and works to move the door in open and closed positions along with the slide. The lock mechanism is located on the door and can move between locked and open positions. A single motor on the door is connected by the power drive system and the locking mechanism. The power drive system, thereby moving the sliding door along with the slide in open and closed positions. The motor ensures that the lock mechanism is in the locked position when the power drive system moves the sliding door to the closed position [2].

The literature and patent studies conducted in this context are summarized as follows.

Labonde and Menke designed a system that uses a stranded cable to keep the vehicle door closed, with the spring winding connected between the body and the drum, allowing the drum to rotate the cable around itself and move the door to the closed position [3]. Kleefeldt et al. designed an electric sliding door system with electronically controlled actuators [4]. Kleefeldt et al. studied the design of an electric sliding door with a belt system for a sliding door with a slide mechanism [5]. Menke developed a design for powered sliding doors by using a cable drive system [6]. Faubert et al. worked on an electronically controlled sliding door mechanism for manually operated sliding door systems [7]. Naganuma developed a system that detects malfunctions by designing a driver circuit and a controller to control the sliding door of a vehicle [8]. Oxley worked on a pinion gear and a belt mechanism that transfers power from the motor to the pinion gear so that a rock door can be opened 
and closed [9]. Osmura et al. studied that the experimental and simulation results between the current and the ideal door create the same feeling by the proposed controller both feedforward and feedback according to the virtual movements of an ideal door, which creates a sense of comfort for automotive sliding doors [10]. Oberheide studied the electronic controller that starts the engine with the feedback signal generated by the sensors to overcome the back driving force of the motor and the belt friction force generated during the manual movement of the door [11]. Oxley has developed a cable drive transmission mechanism to transmit engine power that can be electronically controlled in a sliding door system [12]. Franc et al. worked on automatic sliding door control software on sensitive door movement, adaptive control, and detection of door hardware capacity (motor power) [13]. Oladunmoye et al. observed that the operating behavior of automatic sliding door systems using an infrared sensor [14]. Nishida et al. worked on an intelligent door system. This door system detects people nearby and opens and closes the door with the appropriate opening and closing time [15]. Chomo et al. designed and developed the low-cost automatic sliding door system with the appropriate sensor, electric motor and raw material [16]. Mutlu et al. worked on a generic automatic sliding door mechanism with a rope mechanism that can fit all vehicle types [17].

\section{PSLD (Powered sliding door) Configurations}

According to the literature and patent research on the electrical sliding door system, 3 types of power transmission are used in this type of system. The power transmission types are shown in Figure 2.These transmission types are rack-pinion gear systems, pulleyrope systems and pulley-belt systems. Besides, it has been observed that these systems are packaged in 2 types of the power transmission mechanism, hidden and open. The package types are shown in Figure 3.
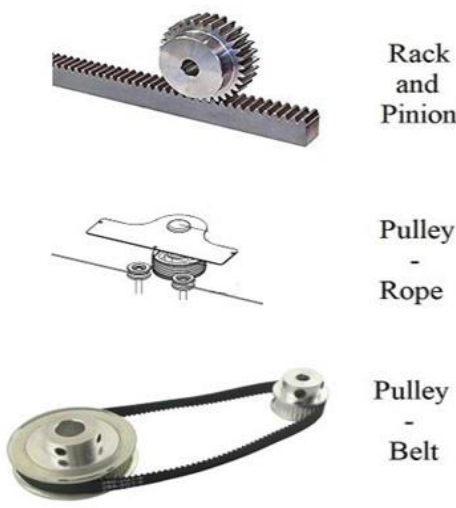

Fig. 2. The power transmission types of the powered sliding door

The companies (Veldo, Ikomat, Revar, Engin oto, etc.) that produce PSLD systems and solutions in our country produce in a quality that can only provide the opening and closing function, which is the most basic function of a sliding door. These companies offer an after-sales service rather than meeting the demands of the OEMs (Original Equipment Manufacturer). Similarly, traction mechanism, gear reduction, motor power, control algorithms and the materials of the components that make up the system will be examined in benchmark studies planned to be made for the products of companies providing after-sales services.

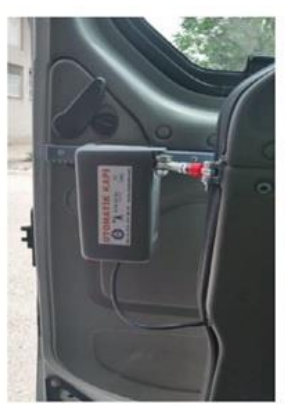

Open Package

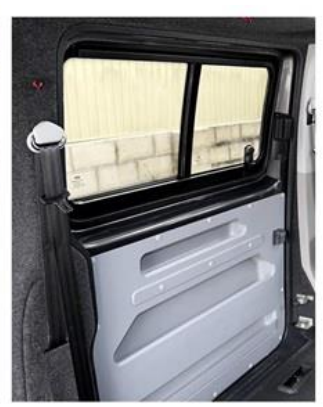

Hidden Package

Fig. 3. The package types of the powered sliding

The products of PSLD producers abroad (Kiekert, Vitte, Magna Closures etc.) were examined in terms of electronic control units, control algorithms, obstacle recognition systems and sensors. For the PSLD system in foreign competitors, it has been observed that products that meet the minimum and maximum limits are developed by taking customer specifications and the requirements in international standards into account. However, an obstacle recognition system with combined information from current and inclination sensors has not been encountered. In this study, an algorithm is developed to prevent getting stuck and accidents due to the missing calculations depending on the vehicle inclination.

\section{Design Requirements and Constraints}

The regulations and specifications used in some OEMs for the electric sliding door are summarized in Table 1 . Where, requirements such as security functions, door mechanisms, general construction, audible signals, warning notifications, electromagnetic interference are included briefly.

Generally, the PSLD system can operate at $17 \%$ slope at temperatures between $-40^{\circ} \mathrm{C}$ and $+82 / 85^{\circ} \mathrm{C}$, the electronic control unit can operate between $9.5 \mathrm{~V}$ and $16 \mathrm{~V}$, an average lifetime should be of 45000 cycles of opening / closing or 7 years 500000 $\mathrm{km}$, the operation should be $95 \%$ error-free, the sound noise generated during operation does not exceed 25 sones, the maximum force applied by PSLD mechanism in operation should be $300 \mathrm{~N}$, the total product weight should not exceed $8 \mathrm{~kg}$, the assembly tolerances $+/-0.2 \mathrm{~mm}$, an alarm should be with a sound of $69 \mathrm{dBA}$ during door opening and closing, it should be ability to withstand corrosion with a coating of up to 36 months for metal parts, it should be ability to complete the salt test for at least 144 hours, the sealing requirements are limited to IP54, the power consumption must not exceed the $15 \mathrm{amps}$, it should operate 5 periods with +18 $\mathrm{V}$ supply above $+85^{\circ} \mathrm{C}$ and 1 period with $+24 \mathrm{~V}$ when below + $25^{\circ} \mathrm{C}$. 
Table 1. OEMs verification requirements of PSLD.

\begin{tabular}{|c|c|}
\hline Code & Requirement Title \\
\hline ISO 26262 & Automotive Safety Integrity Level \\
\hline ECE R11 & $\begin{array}{l}\text { Uniform provisions concerning the approval } \\
\text { of vehicles with regard to door latches and } \\
\text { door retention components }\end{array}$ \\
\hline ECE R21 & $\begin{array}{c}\text { Uniform provisions concerning the approval } \\
\text { of vehicles with regard to their interior } \\
\text { fittings }\end{array}$ \\
\hline ECE R29 & $\begin{array}{c}\text { Uniform provisions concerning the approval } \\
\text { of vehicles with regard to the protection of } \\
\text { the occupants of the cab of a commercial } \\
\text { vehicle }\end{array}$ \\
\hline ECE R107 & $\begin{array}{l}\text { Category M2 or M3 vehicles with regard to } \\
\text { their general construction }\end{array}$ \\
\hline ECE R10 & $\begin{array}{c}\text { Uniform provisions concerning the approval } \\
\text { of vehicles with regard to electromagnetic } \\
\text { compatibility }\end{array}$ \\
\hline ECE R28 & $\begin{array}{l}\text { Uniform provisions concerning the approval } \\
\text { of audible warning devices and of motor } \\
\text { vehicles with regard to their audible signals }\end{array}$ \\
\hline ECE R118 & $\begin{array}{l}\text { Uniform technical prescriptions concerning the } \\
\text { burning behavior and/or the capability to } \\
\text { repel fuel or lubricant of materials used in } \\
\text { the construction of certain categories of } \\
\text { motor vehicles }\end{array}$ \\
\hline ECE R52 & $\begin{array}{l}\text { Uniform provisions concerning the approval } \\
\text { of } \mathrm{M} 2 \text { and } \mathrm{M} 3 \text { small capacity vehicles with } \\
\text { regard to their general construction }\end{array}$ \\
\hline EC $661 / 2009$ & $\begin{array}{l}\text { Requirements for the general safety of motor } \\
\text { vehicles, their trailers and systems, } \\
\text { components and separate technical units } \\
\text { intended therefor }\end{array}$ \\
\hline $\begin{array}{c}2001 / 85 \text { EC } \\
\text { Annex V }\end{array}$ & $\begin{array}{c}\text { Guidelines for measuring the closing forces of } \\
\text { power-operated doors }\end{array}$ \\
\hline 70/388/EEC & Audible warning devices for motor vehicles \\
\hline 70/387/EEC & Doors of motor vehicles and their trailers \\
\hline 74/60/EEC & Interior fittings of motor vehicles \\
\hline 2001/85/EC & $\begin{array}{l}\text { Special provisions for vehicles used for the } \\
\text { carriage of passengers comprising more than } \\
\text { eight seats in addition to the driver's seat }\end{array}$ \\
\hline 2004-104/EC & $\begin{array}{l}\text { Radio interference (electromagnetic compatibili } \\
\text { ty) of vehicles }\end{array}$ \\
\hline
\end{tabular}

Table 2. Design requirements and criteria of PSLD.

\begin{tabular}{c|c}
\hline Success Criteria & Desired Requirements \\
\hline $\begin{array}{c}\text { PSLD can open and close the door } \\
\text { when the vehicle is on a slope }\end{array}$ & $17 \%$ Slope \\
\hline $\begin{array}{c}\text { Providing the function of the PSLD } \\
\text { above or below certain battery volt- } \\
\text { ages }\end{array}$ & $\begin{array}{c}\text { Correct operation capability be- } \\
\text { tween 9.5 V and 16 V and current } \\
\text { consumption should not exceed } \\
15 \text { Amps }\end{array}$ \\
\hline $\begin{array}{c}\text { During the opening / closing of the } \\
\text { PSLD, it does not make a noise } \\
\text { above a certain value. }\end{array}$ & Must not exceed 25 Sones \\
\hline $\begin{array}{c}\text { Limiting the maximum force to be } \\
\text { applied during the process and not } \\
\text { exceeding the total product weight }\end{array}$ & Must not exceed $300 \mathrm{~N} \mathrm{and} 8 \mathrm{~kg}$ \\
\hline Maximum door speed & Must not exceed $0.25 \mathrm{~m} / \mathrm{sec}$ \\
\hline \multicolumn{2}{c}{}
\end{tabular}

In this study, the design requirements and success criteria of the PSLD are summarized in Table 2.

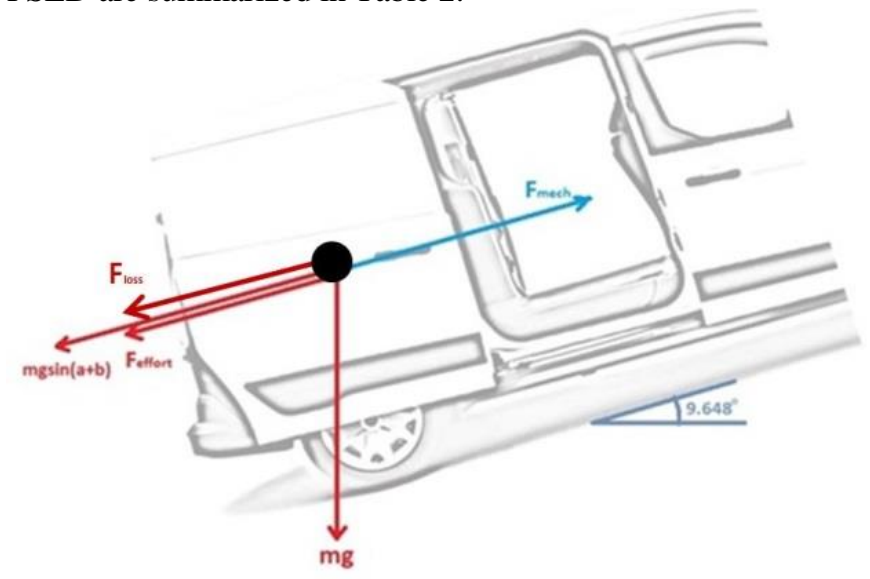

Fig.4. The forces acting on a sliding door

\section{Design of PSLD}

\subsection{The Design of Main Drive Unit of PSLD}

Basically, the forces acting on a sliding door are shown in Figure 4. These forces are the inclination of the vehicle $(m \cdot g \cdot \sin (a+b))$, the friction force $\left(F_{\text {effort }}\right)$ and the mechanical losses $\left(F_{\text {loss }}\right)$. Eq.1 gives the formula for the force needed to move the sliding door.

$m \cdot a_{\text {door_accelaration }}=F_{\text {mech }}-m g \sin (a+b)-F_{\text {effort }}-F_{\text {loss }}$

In this study, the rack and pinion gear structure, which stands out with its ease of use, cost and safety features, was used. In this direction, when the formulas from Eq. 1. and vehicle properties are taken into consideration, the force requirement calculations are shown in Table 3.

Table 3. The required force calculations of the PSLD.

\begin{tabular}{l|c}
\hline Door mass of the vehicle & $50 \mathrm{~kg}$ \\
\hline Slide slope & 1 degree \\
\hline Acceleration Range & From $0.3 \mathrm{~m} / \mathrm{s}^{2}$ to $0.62 \mathrm{~m} / \mathrm{s}^{2}$ \\
\hline Maximum vehicle slope & $17 \%$ \\
\hline The friction force & $20 \mathrm{~N}$ \\
\hline The mechanical loss & $20 \mathrm{~N}$ \\
\hline The inclination force & $90 \mathrm{~N}$ \\
\hline The minimum required force & $40 \mathrm{~N}$ \\
\hline The maximum required force & $130 \mathrm{~N}$ \\
\hline
\end{tabular}

The KORMAS 12V (671 190 57) electric motor is used in this study, as it meets the automotive standards and is compatible with the desired operating voltages. The torque-current-power-speed characteristic of the electric motor used is shown in Figure 5.

According to the data of Table 2, Table 3 and Figure 5, the required diameter of pinion gear so as to transmit appropriate mechanical power is calculated in Table 4 which shows the door speed, motor power, motor speed, motor torque and radius of the pinion gear. 


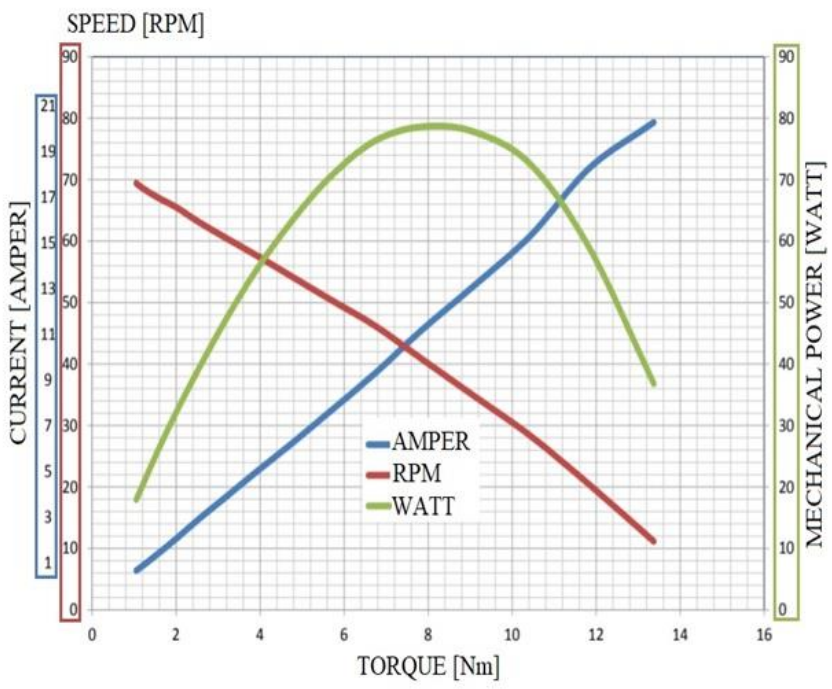

Fig.5. The torque-current-power-speed characteristics of the KORMAS 12V (671 190 57) electric motor

Table 4. The calculated pinion gear geometry of PSLD

\begin{tabular}{c|c}
\hline Door speed & $0,249 \mathrm{~m} / \mathrm{s}$ \\
\hline Motor power & $32 \mathrm{Watt}$ \\
\hline Motor speed & $36,7 \mathrm{RPM}$ \\
\hline Motor torque & $8,26 \mathrm{Nm}$ \\
\hline Radius of pinion gear & $0,065 \mathrm{~m}$ \\
\hline Transmitted force & $130 \mathrm{~N}$ \\
\hline
\end{tabular}

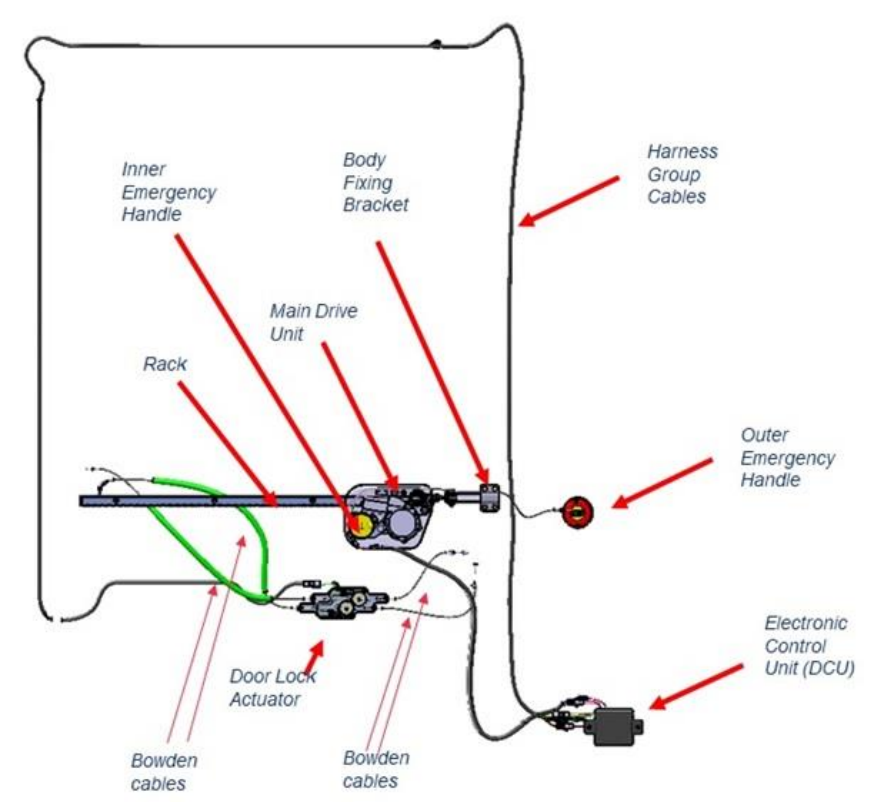

Fig.6. The designed components of the PSLD

After the calculation of the pinion gear and the selection of the electric motor, a design study was carried out on the door. Here, it is also taken into account that the door can be opened from inside and outside in case of emergency, which is one of the special customer requests. In this context, the emergency exit handle rack and pinion gear system, an electromechanical actuator to open the door lock and an electronic control unit were considered. Figure 6 shows components of the PSLD. And Figure 7 and Figure 8 shows the assembly on the vehicle.

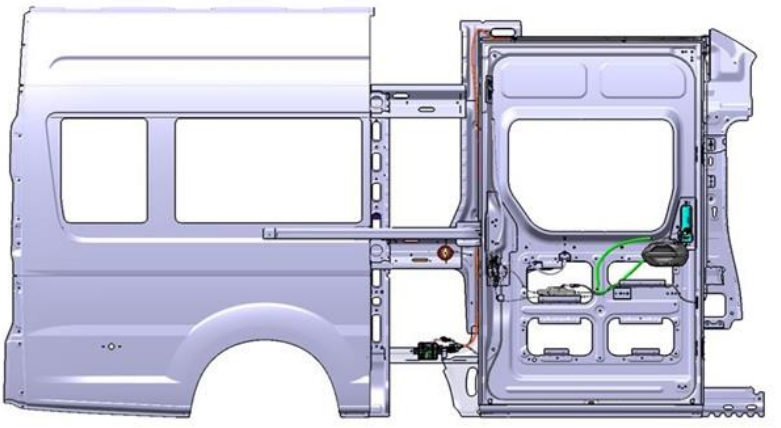

Fig.7. The outside view of assembly of designed PSLD

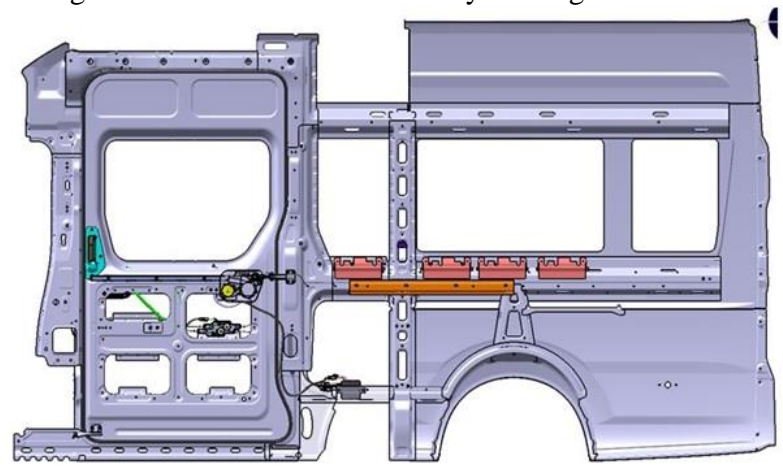

Fig.8. The inside view of assembly of designed PSLD

The main drive unit shown in Figure 6 consists of the electric motor that enables the door to open and close, the crank handle that allows the rack and pinion system to release in case of emergency, a micro switch indicating that the rack and pinion gear system is engaged or disengaged, a position sensor that detects the information that the door is open, with a fixing bracket and a universal joint. Figure 9-11 show the detailed views of the main drive unit.

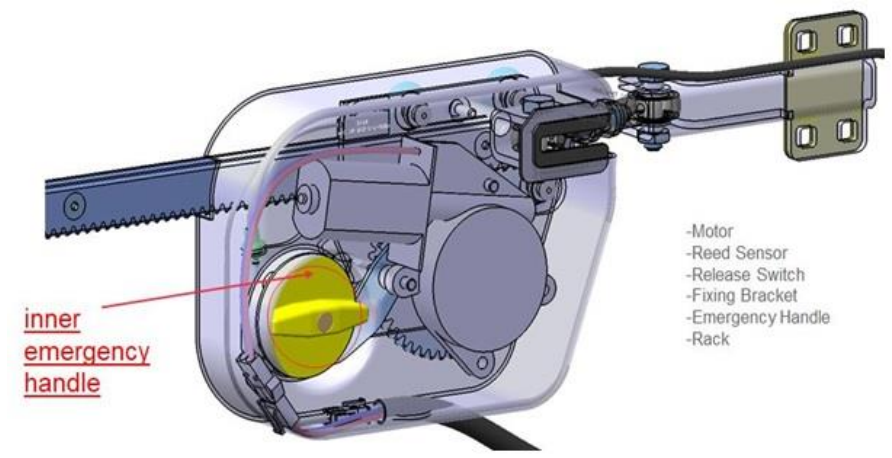

Fig.9. The view of main drive unit of designed PSLD 


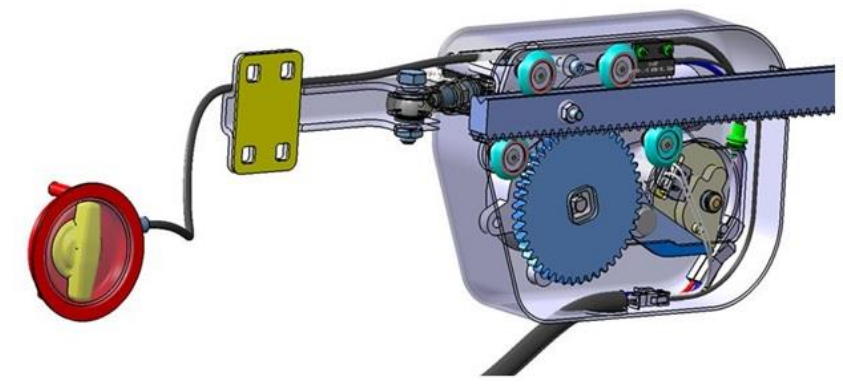

Fig.10. The detailed view 1 of main drive unit of designed PSLD

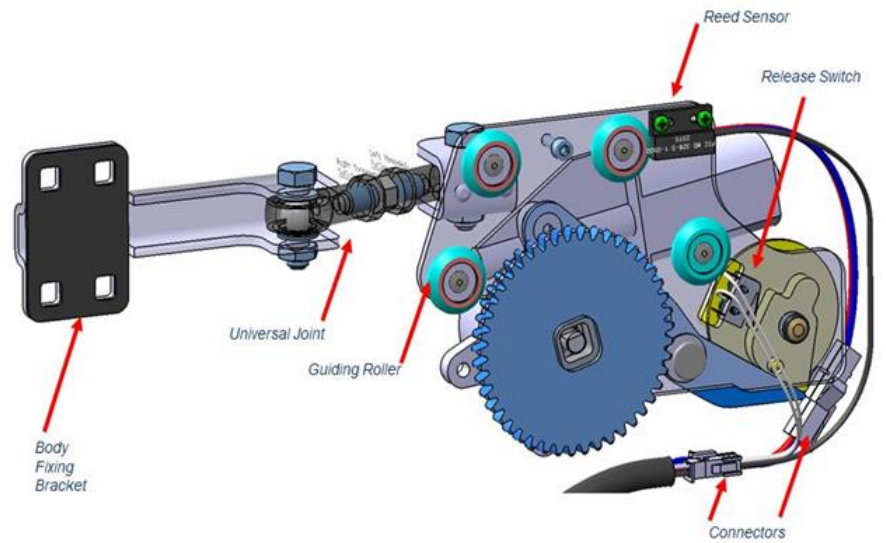

Fig.11. The detailed view 2 of main drive unit of designed PSLD

In order to meet the noise criterion, by using the guidance roller system, mechanical noise is prevented, and the results obtained in the previous tests are 4 Sones (Approx.. $48 \mathrm{~dB}$ ) and it meets the success criteria.

\subsection{The Design of Door Lock Actuator Unit of PSLD}

In this part, the door must be unlocked before the door opening operation starts. It needs an actuator which can provide this process. In addition, a design is developed to enable a parallel actuator and sliding door to operate in order to open by the inner door handle, in line with the customer's special request. Detailed visuals of this design are shown in Figure 12 and Figure 13.

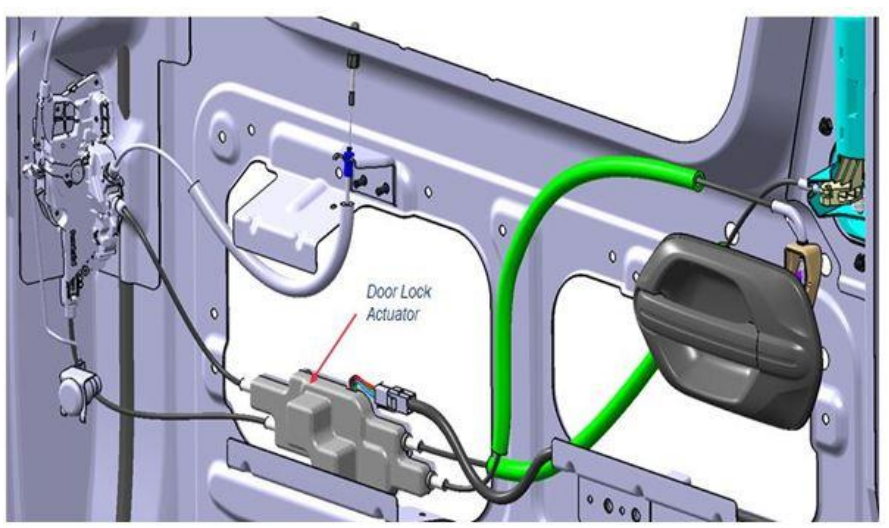

Fig.12. The view of the door lock actuator unit of designed PSLD

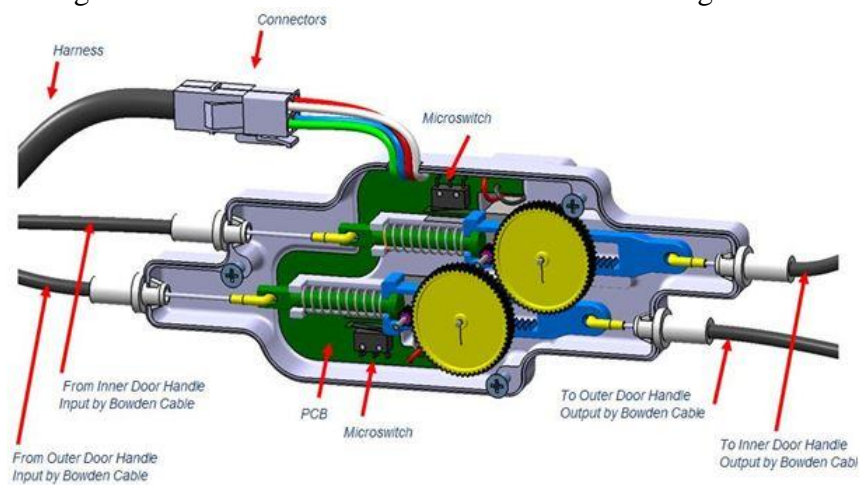

Fig.13. The detailed view of the door lock actuator unit of designed PSLD

As can be seen in Figure 13, the actuator consists of 2 electric motors with parallel mechanism, 2 gear system, 2 helical springs to take the first position of the system, 2 microswitches to read the status information of the lock, 2 bowden cables as inputs and outputs to move the lock.

The force required to open the door lock is $15 \mathrm{~N}$. The system is designed according to the relevant requirements of JLR [18-20]. The electric motors used in the system are Mabuchi FC280SC. Typically the motor used in door actuators is preferred and compatible with automotive requirements.

\subsection{The Design of Electronic Control Unit of PSLD}

DCU (Electronic Control Unit) creates and obtains signals to provide communication between the drive unit and door actuator. It also controls the current values of units in order to control transmitted forces and door speed etc. DCU has real time operating system. DCU controls the main drive motor by depending on battery voltage and motor current consumption so that DCU provides both safety actuation and exact time control. Figure 14 and Figure 15 show the detailed views of DCU.

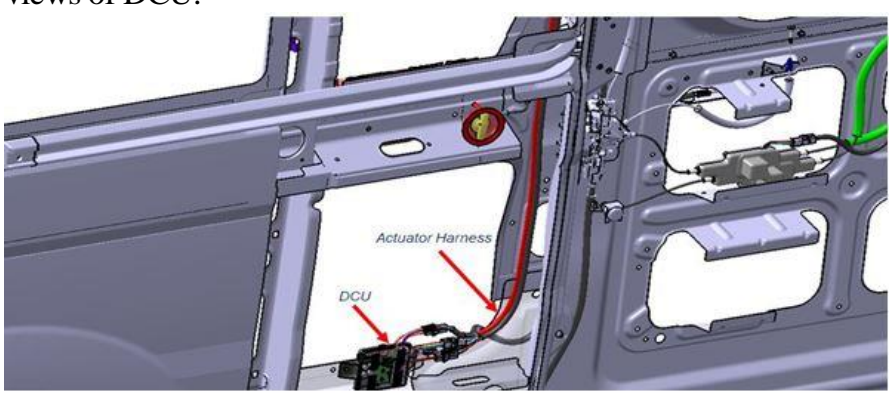

Fig.14. The view of the DCU of designed PSLD 


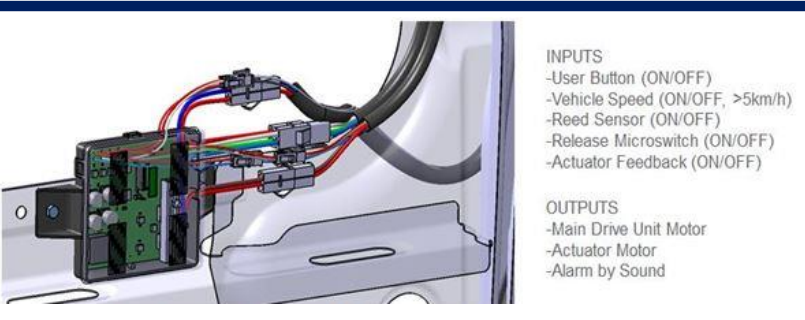

Fig.15. The detailed view of the DCU of designed PSLD

DCU reads user buttons, vehicle speed, reed sensor, inclination sensor, release microswitch and actuator feedback as inputs. Then, DCU controls the main drive motor, actuator motors and alarm by sound as outputs. DCU block diagram and PCB (Printed Circuit Board) design are shown in Figure 16 and Figure 16, respectively.

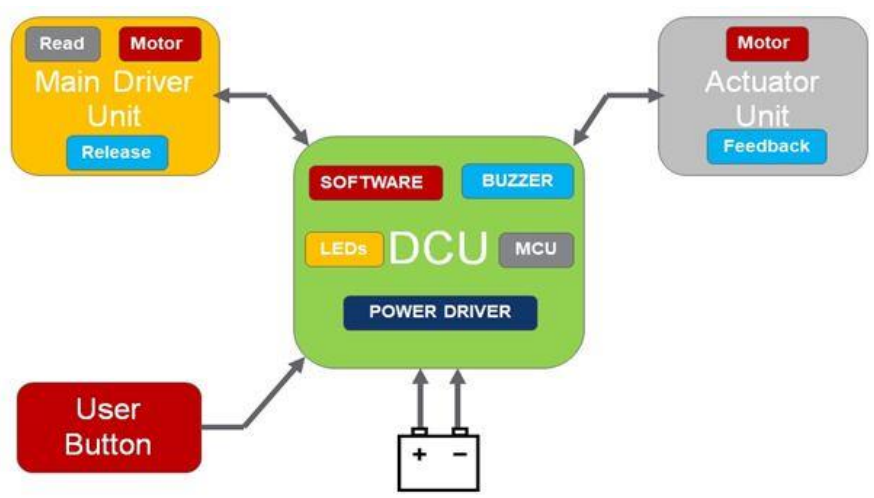

Fig.16. The DCU block diagram

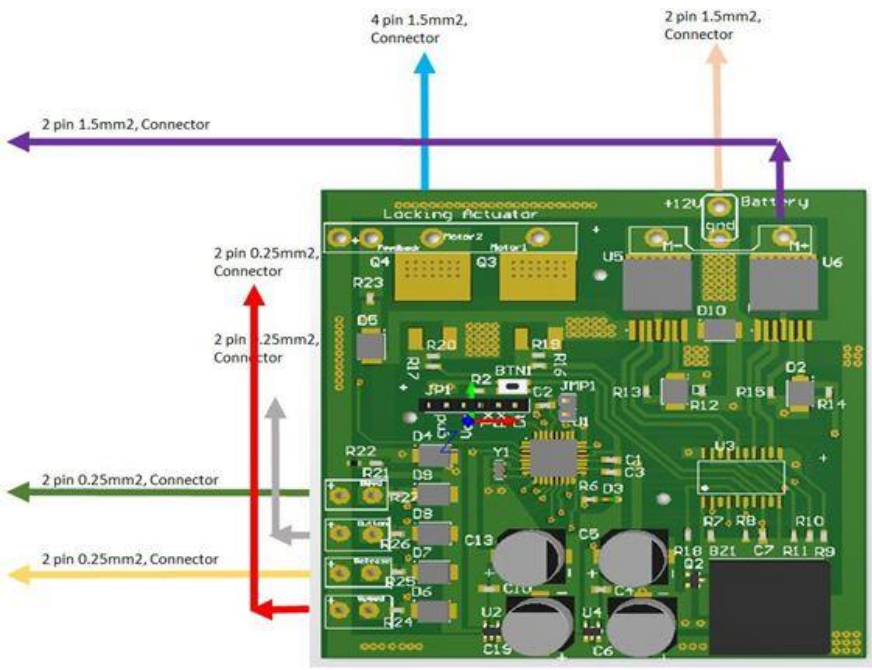

Fig.17. The PCB design of DCU

The nominal operating voltage for the main unit motor used here is 12 Volts. The desired operating conditions are between 9.5 Volts and 16 Volts, and the motor can provide the desired output torque and speed under these operating conditions. Due to the regulator used on the PCB, the microcontroller is designed to work stably without being affected by voltage fluctuations. In addition, the current drawn by the motor is used as feedback and the torque control of the motor limits the $300 \mathrm{~N}$ force and the maximum current value does not exceed 15 Amps, provided by the microcontroller on the PCB. However, during the opening and closing of the door, passengers and the driver must be warned by an alarm. The alarm intensity is expected to be at a minimum level of $69 \mathrm{~dB}$. This requirement is met by the piezzo buzzer $(12 \mathrm{~V}, 83 \mathrm{~dB}, 4.0 \mathrm{kHz})$.

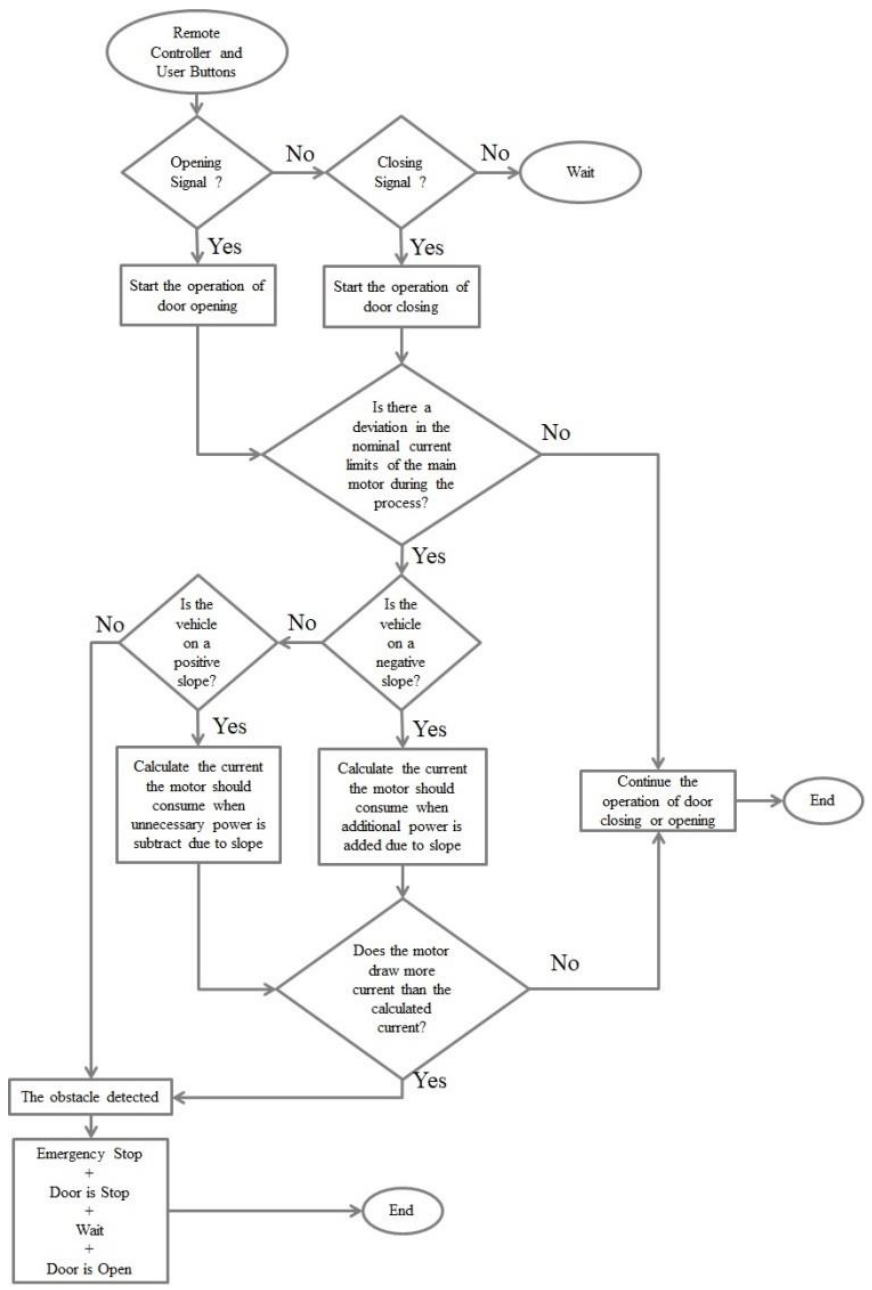

Fig.18. The flow chart of control algorithm

\subsection{The Design of Control Algorithm of PSLD}

Here, the details of the algorithm running on the electronic control unit are given. First of all, the opening or closing command detected by the user buttons or the remote control is processed. It is determined that the received signal is an opening or closing command. Then, the opening or closing operation of the door is started. During the opening or closing operation, the current from the main unit motor is read continuously and it is checked whether it is within the limit values. Whether there is an obstacle between the door is checked depending on whether the vehicle is on the slope and the amount of current drawn, and if necessary, the door opening or closing process is 
stopped. The flow chart including the working algorithm of the electronic control unit is shown in Figure 18.

\section{Prototyping Studies}

In this section, the prototyping studies of the product are carried out. Figure 19 shows electrical wiring cables, rack, electronic control unit and its covers, out of body emergency valve and its bowden cable, main unit cover, programming and debugging tools, user buttons, actuator and its mechanical parts (bowden cable, links), main unit. Where, most materials part are chosen by off shelves. The rest of parts are produced by machining and $3 \mathrm{D}$ printing. The total weight of the designed PSLD is $6.4 \mathrm{~kg}$.

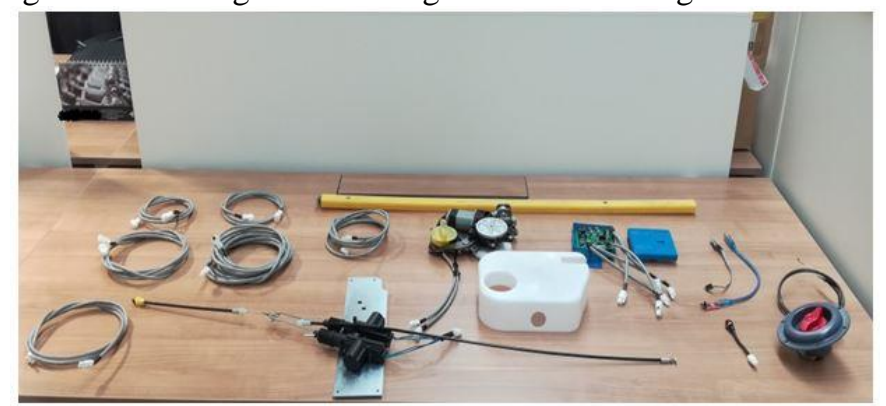

Fig.19. The prototyping view of designed PSLD

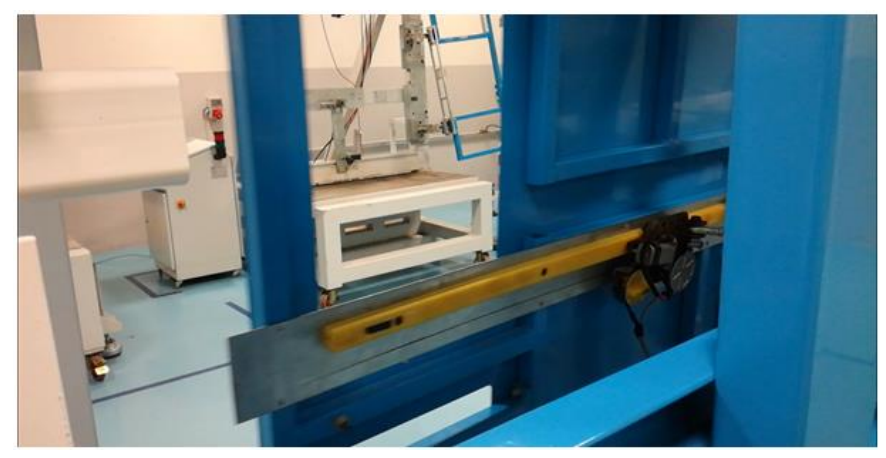

Fig.20. The designed PSLD on the test bench

\section{Test Results}

The verification criteria for the prototype of the PSLD are checked on the test bench. Figure 20 shows the PSLD mounted on the test bench. The opening and closing tests of the door are carried out considering the nominal voltage $(12 \mathrm{~V})$, operating voltage range $(9.5 \mathrm{~V}-16 \mathrm{~V})$, and the criteria for the vehicle to be on slope. Besides, the algorithm of obstacle detection is tested in here.

Figure 21 shows no slope test at the nominal voltage (12V). As can be understood in Figure 21, all criteria in Table 2 regarding the maximum current, maximum applied torque, and door speed are met.

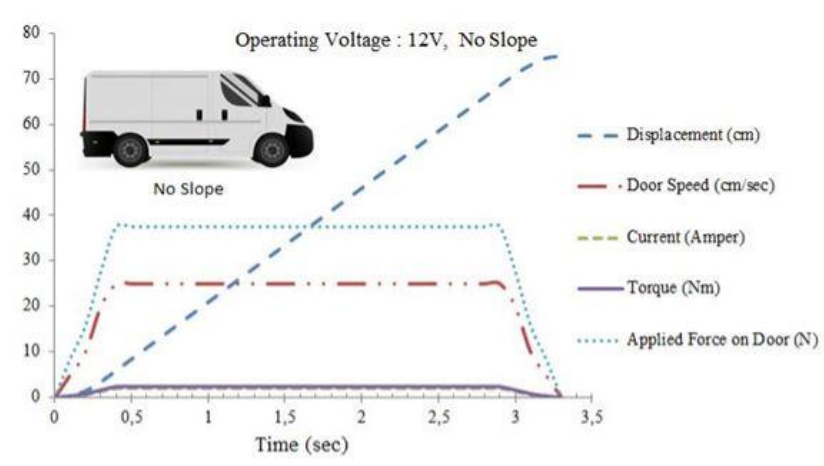

Fig.21. The opening operation test of PSLD (No slope, nominal voltage)

Similarly, Figure 22 shows the slope test at the nominal voltage $(12 \mathrm{~V})$. Same as here, it is observed that all criteria in Table 2 regarding to the maximum current, maximum applied torque, and door speed are met.

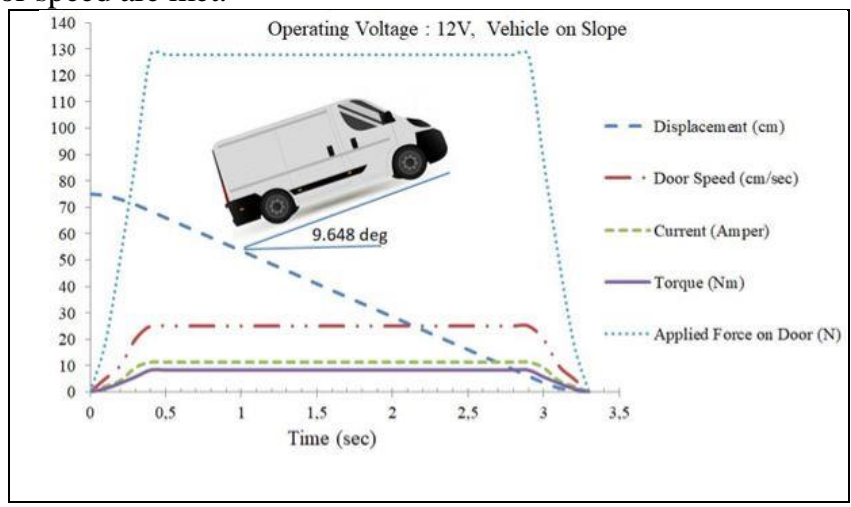

Fig.22. The closing operation test of PSLD (17\% slope, nominal voltage)

On the other hand, the low voltage operating test at $9.5 \mathrm{~V}$ is performed. The obtained results are shown in Figure 23 shows reduction of the door speed in comparison with the nominal voltage test. The total duration of the opening operation of the door is reached to 4.5 seconds by increasing by 1.2 seconds.

The high voltage operating test at $16 \mathrm{~V}$ is realized. Due to the PWM controller on DCU for the main drive electric motor, the DCU regulates and reduces the voltage on the input of electric motor. Therefore, there is no any change in the operation characteristics of PSLD, the results are shown in Figure 24.

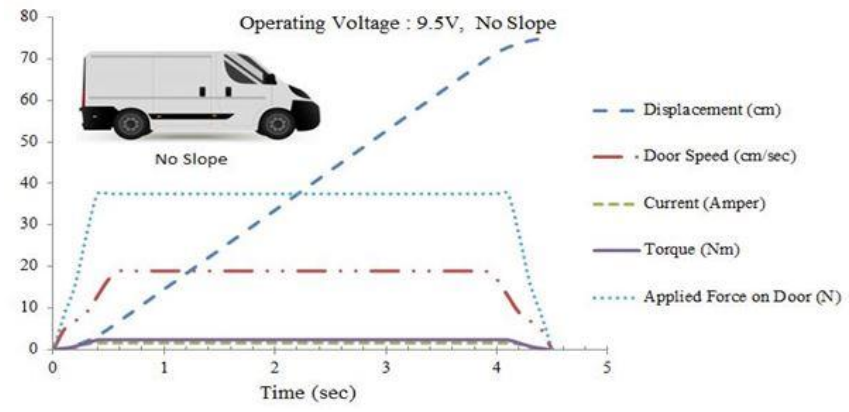

Fig.23. The opening operation test of PSLD (No slope, 9.5V) 


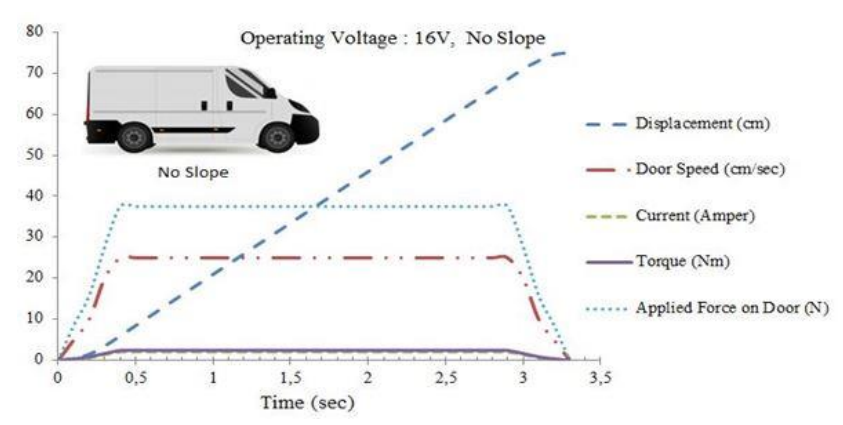

Fig.24. The opening operation test of PSLD (No slope, 16V)

The obstacle detection process is carried out to prevent passengers from getting stuck in the door and accidents while getting on or off the vehicle. In this study, this test is carried out by taking into account the current drawn over the main unit and the additional forces arising from the vehicle slope during the closing of the door by keeping a passenger on the test bench at the part where the door is opened. Figure 25 shows the operation of a standing passenger and PSLD on the test bench. On the other hand, the obtained data during this test are shown in Figure 26. As can be understood from Figure 26, when the current drawn by the main unit motor is 15 Amp., the force applied by the door is $170 \mathrm{~N}$ and the electronic control unit first stops the closing process and then starts the opening of the door. It is observed that the door in the design requirements meets the maximum current (15 Amp.) criteria with the criterion that it should not exceed the maximum 300N.

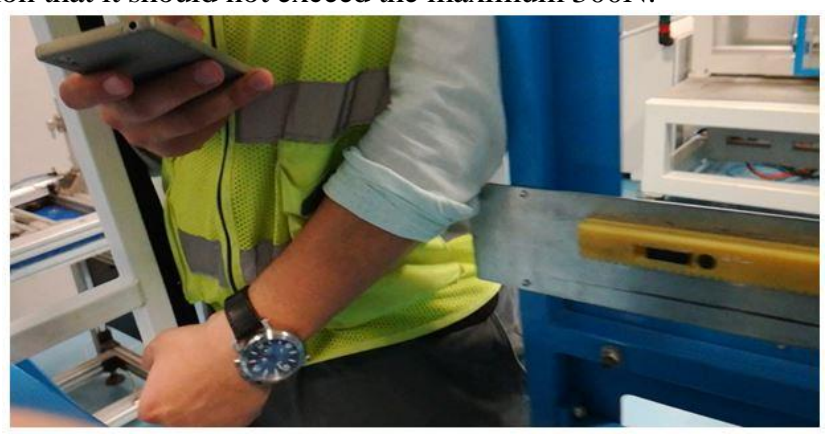

\section{Conclusions}

Fig.25. The obstacle detection on the test bench

In this study, a PSLD system design and its prototype are realized. Firstly, the main unit of the PSLD is designed by determined the design criteria and constraints. Secondly, the door lock actuator is developed, and then the electronic control unit design and algorithm are developed. Finally, compliance with the design criteria is tested.

The PSLD prototype meets the design requirements such as audible noise, operation alarm and prototype weight. The properties of PSLD prototype and design requirements are shown in Table 5. Where it is observed that all values are in the limit given in Table 2.
Operating Voltage : $12 \mathrm{~V}$, No Slope, Obstacle Detection Test

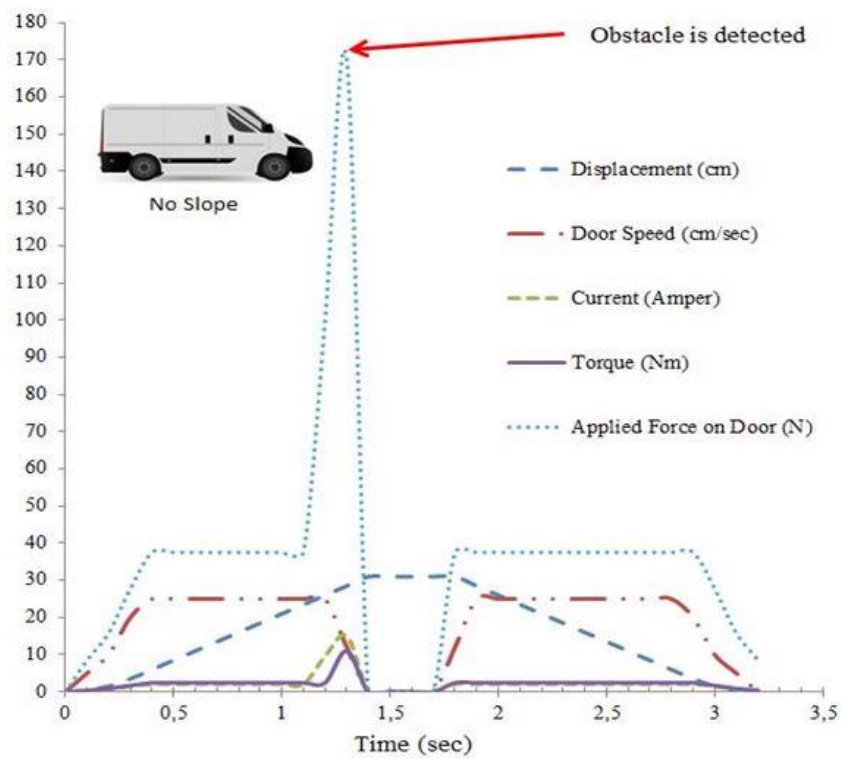

Fig.26. The results of the obstacle detection

Table 5. The properties of PSLD prototype

\begin{tabular}{l|l|l}
\hline & Prototype Status & Criteria \\
\hline $\begin{array}{l}\text { Noise } \\
\text { (Squeak \& Rattle) }\end{array}$ & $\begin{array}{l}\text { 4 Sones } \\
\text { (Approx. 48dB) }\end{array}$ & $\begin{array}{l}\text { Not to exceed 25 } \\
\text { Sones }\end{array}$ \\
\hline Operation Alarm & Up to 83dB & Minimum 69dB \\
\hline Prototype Weight & $6.4 \mathrm{~kg}$ & Maximum 8kg \\
\hline
\end{tabular}

The PSLD prototype is tested in accordance with the design criteria. These tests are the opening test at nominal voltage, the sliding door closing test when the vehicle on the slope, the door opening tests under the minimum and maximum operating voltage and finally the obstacle detection tests. The test results are summarized in Table 6.

As can be seen from Table 5 and Table 6, the obtained results meet the design requirements given in Table 2 . The selection of the electric motor used in the main unit plays an important role in meeting the success criteria. And it provides the system to work with approximately 1.76 safety factor. In the low operating voltage $(9.5 \mathrm{~V})$ test given in Table 5, the door speed decreased by $24 \%$, and leading to a delay for the closing of the door for 1.2 seconds. This situation is not considered as a problem and the test is confirmed as the main function of the door is provided.

In addition, it was observed that the obstacle detection process works successfully by using the vehicle inclination sensor and motor current information. Therefore, a product development study is carried out in which functional safety is ensured by preventing errors that are frequently encountered in obstacle detection processes. 
Table 6. Test results of PSLD prototype

\begin{tabular}{|c|c|c|c|c|c|}
\hline $\begin{array}{c}\text { Verification } \\
\text { Tests }\end{array}$ & 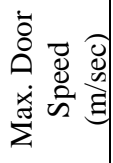 & 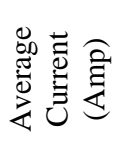 & 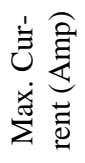 & 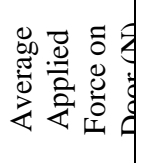 & 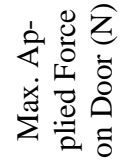 \\
\hline $\begin{array}{l}\text { The opening } \\
\text { operation } \\
\text { test of PSLD } \\
\text { (No slope, } \\
\text { nominal } \\
\text { voltage) }\end{array}$ & 0,25 & 2,1 & 2,1 & 37,5 & 37,5 \\
\hline $\begin{array}{l}\text { The closing } \\
\text { operation } \\
\text { test of PSLD } \\
\text { (17\% slope, } \\
\text { nominal } \\
\text { voltage) }\end{array}$ & 0,25 & 11,3 & 11,3 & 127,8 & 127,8 \\
\hline $\begin{array}{l}\text { The opening } \\
\text { operation } \\
\text { test of PSLD } \\
\text { (No slope, } \\
9.5 \mathrm{~V} \text { ) }\end{array}$ & 0,19 & 1,7 & 1,7 & 37,5 & 37,5 \\
\hline $\begin{array}{l}\text { The opening } \\
\text { operation } \\
\text { test of PSLD } \\
\text { (No slope, } \\
16 \mathrm{~V} \text { ) }\end{array}$ & 0,25 & 2,1 & 2,1 & 37,5 & 37,5 \\
\hline $\begin{array}{c}\text { The Obsta- } \\
\text { cle detection } \\
\text { test }\end{array}$ & 0,25 & 2,1 & 15 & 37,5 & 170 \\
\hline
\end{tabular}

\section{Acknowledgment}

This study was supported by TUBITAK/TURKEY in frame of the project code of 3160977 as researchers, I would like to thank the TUBITAK/TURKEY and Rollmech Automotive A.Ş.

\section{Nomenclature}

$\begin{array}{ll}F_{\text {mech }} & : \text { the required force to open or close the door }(\mathrm{N}) \\ F_{\text {effort }} & : \text { friction force }(\mathrm{N}) \\ F_{\text {loss }} & : \text { mechanical losses force }(\mathrm{N}) \\ m & : \text { door mass of vehicle }(\mathrm{kg}) \\ g & : \text { gravity }\left(\mathrm{m} / \mathrm{sec}^{2}\right) \\ a & : \text { slide slope }(\text { degree }) \\ b & : \text { vehicle slope (degree) }\end{array}$

\section{Conflict of Interest Statement}

The author declares that there is no conflict of interest.

\section{References}

[1] Arpacioğlu M , Fenercioğlu A, Avşar Y. Doğrusal Relüktans Motorun Otomatik Kayar Kapılara Uygulanması ve PIC Mikrodenetleyici ile Kontrolü. Gaziosmanpaşa Bilimsel Araştırma Dergisi. 2018; 7(3): 12-26.

[2] Murray S, Fremmer TP, Daniel AR. Power sliding mini-van door. Atoma International Inc. US 6125583A, 1998.

[3] Labonde D, Menke JT. Electrical-cable system for motor-vehicle sliding door. Kiekert AG. US 6076883 A, 1988.

[4] Kleefeldt F., Labonde D., Menke J.T., Armbruster S. and Schonenberg T.,"Motor-vehicle sliding-door system with electronic controller", Kiekert AG, US 5836639 A, 1997.

[5] Kleefeldt F, Labonde D, Menke JT, Armbruster S, Schonenberg T. Motor-vehicle sliding-door system. Kiekert AG, US 5876087 A, 1997.

[6] Menke JT. Cable drive for motor-vehicle sliding-door. Kiekert AG. US 5992919 A, 1998.

[7] Faubert RJ, Brock WT, Haskin TW, Kapes RC. Power sliding door for a motor vehicle. DaimlerChrysler Corporation. US 6079767 A, 1999.

[8] Naganuma T. System for controlling vehicle power sliding door. Keihin Corporation. US 6525499 B2, 2001.

[9] Oxley PL. Belt-driven rack gear power sliding door. Magna Closure Inc. US 7810282 B2, 2007.

[10]Osamura K, Kobayashi S, Hirata M, Okamoto H. Power assist control for slide doors using an ideal door model. IEEE International Symposium on Industrial Electronics, Cambridge, UK, 2008, pp. 1293-1299, Available from: http://doi.org/10.1109/ISIE.2008.4676973.

[11]Oberheide GC. Belt-driven power sliding door with belt tensioner. Magna Closure Inc. US 8464469 B2, 2008.

[12] Oxley PL. Compact cable drive power sliding door mechanism. Magna Closure Inc. US 7866732 B2, 2008.

[13]Franc H, Karel J, Slavko C. Mechatronic Control System on a FiniteState Machine. Automatika: 54:1, 126-138, 2013. Available from: http://doi.org/10.7305/automatika.54-1.298.

[14]Oladunmoye M, Oluwatomi AA, Obakin O. Design And Construction of an Automatic Sliding Door Using Infrared Sensor. Computing, Information Systems, Development Informatics \& Allied Research Journal : Vol. 5 No. 4. 2014. Available from : https://www.researchgate.net/publica-

tion/338430785_DESIGN_AND_CONSTRUCTION_OF_AN_AU TOMATIC_SLIDING_DOOR_USING_INFRARED_SENSOR

[15]Daiki N, Kumiko T, Shunsuke K, Kazuo T, Tatsuhiro M, Norihiro A, Toshihiro M, Takashi S, Tetsuo T. Development of Intelligent Automatic Door System. IEEE International Conference on Robotics and Automation (ICRA), Hong Kong, China, 2014, pp. 6368-6374. Available from: http://doi.org/10.1109/ICRA.2014.6907799.

[16]Chomo DIG, Yawas DS, Johnson ZS. Development of an Automatic Door System. American Journal of Engineering Research (AJER): vol. 7, issue 5, pp.168-173, 2018. Available from: http://www.ajer.org/papers/Vol-7-issue-5/T0705168173.pdf

[17]Mutlu H, Yapanmış B, Günöz A. Automotic Sliding Door Rope Mechanism Design for Vehicles. Turkish Journal of Engineering, c. 
2, say1. 2, ss. 49-53, May. 2018. Available from: http://doi.org/10.31127/tuje.339946.

[18]Demir U, Aküner MC. Investigation of the immunity to voltage over stress requirement for the electrical seat latch actuator. ICEEE 4th International Conference on Electrical and Electronic Engineering, Ankara, 2017, pp. 187-193. Available from: http://doi.org/ 10.1109/ICEEE2.2017.7935817.

[19]Demir U. Design and Analysis of Solenoid Actuator for Vehicle Foldable Seat Structure. International Journal of Advances in Engineering and Pure Sciences, vol. 32, no. 2, pp. 158-171, Jun. 2020. Available from: http://doi.org/10.7240/jeps.586258.

[20]Kamış Z, Demir U. Design and Optimization of Electromechanical Actuator for the Latch of Foldable Vehicle Seats. Material Testing Journal, vol. 62, issue 7, pp. 749-755, Jul 2020. Available from: http://doi.org/10.3139/120.111539. 